\title{
REFERENCE VALUES FOR THE OPHTHALMIC SCHIRMER TEAR TEST AND THE INTRAOCULAR PRESSURE IN HEALTHY CHINCHILLAS
}

\author{
Richards, M., Trbolová, A. \\ Clinic of Small Animals, Department of Surgery, Orthopaedics, Radiology and Reproduction \\ University of Veterinary Medicine and Pharmacy, Komenského 73, 04181 Kosice \\ The Slovak Republic
}

alexandra.trbolova@uvlf.sk

\section{ABSTRACT}

The objective of this study was to measure the intraocular pressure (IOP) and tear production before and after topical anaesthesia in healthy chinchillas (Chinchilla lanigera). Thirteen healthy non-sedated chinchillas (eight males and five females) were used in this study. The tear production was measured by the novel endodontic paper point tear test (PPTT) using Roeko Colour No. 30 Paper points. Following the PPTT, one drop of $0.4 \%$ oxybuprokainium chloride was added to the eye to anaesthetise the cornea and the IOP was measured using the Tono-Pen Avia ${ }^{\oplus}$ Vet. Excess anaesthetic was removed from the conjunctival fornix using a sterile cotton tipped applicator and the PPTT II was performed. The PPTT I and II were measured in 26 eyes, mean \pm standard deviations (SD) were $7.98 \pm 1.95 \mathrm{~mm} \cdot \mathrm{min}^{-1}$, and $9.71 \pm 3.52 \mathrm{~mm} \cdot \mathrm{min}^{-1}$ respectively. The IOP was measured in 20 eyes, and the mean \pm SD was $28.52 \pm 12.48 \mathrm{mmHg}(35.50 \pm 9.31 \mathrm{mmHg}$ in males and $21.53 \pm 11.57 \mathrm{mmHg}$ in females). There was no significant difference in the PPTT results between the left and right eyes or between the male and female groups. The males were found to have a significantly higher IOP than females and the PPTT II was significantly greater than the PPTT I. The PPTT test proved to be effective, easy to use, and reliable, causing little apparent discomfort to the chinchillas and could prove to be a much more effective tool than the Schirmer tear test for the evaluation of the tear production in animals with small eyes and/or low aqueous tear production. The mean intraocular pressure proved to be much higher in this population of chinchillas than those previously studied and so further investigation is warranted before a reliable reference range may be produced.

Key words: eye; healthy chinchilla; intraocular pressure; Schirmer tear test

\section{INTRODUCTION}

Chinchillas are particularly predisposed to developing keratoconjunctivitis sicca due to their relatively large and prominent corneas, low blink frequency, and exposure 
to a potentially dusty environment from low quality dust baths or poor hygienic conditions $[8,10]$. It is, therefore, essential that normal tear production values are known and that keratoconjunctivitis sicca can be diagnosed promptly. The Schirmer tear test (STT) has previously been used to assess the aqueous tear production in chinchillas, however, the results were difficult to interpret due to the very low amount of tears produced with a mean \pm standard deviation (SD) of $1.07 \pm 0.54 \mathrm{~mm} \cdot \mathrm{min}^{-1}$. The tear level sometimes did not even reach the notch in the test strip $[7,11]$. The phenol red thread test was also used to assess the aqueous tear production in chinchillas and it produced more readable results with a mean \pm SD of $14.6 \pm 3.5 \mathrm{~mm} .15 \mathrm{~s}^{-1}$ [11] A more accurate and reliable method of tear detection in this species and in other animals with small palpebral fissure lengths and low aqueous tear production, would be of great benefit. Several studies have used the novel endodontic paper point tear test (PPTT) in animals with small palpebral fissure lengths to assess the aqueous tear production with promising results $[4,5,6]$. In our study we assessed the suitability, reliability and ease of use of the novel endodontic paper point tear test (PPTT), and established a reference range as a basis for further investigations into this promising new test method.

There are few reports in the literature of raised intraocular pressure (IOP) due to primary glaucoma in chinchillas, however, luxation of the lens, cataracts and lens induced uveitis have been reported to cause secondary glaucoma $[3,8,15]$. Only three papers have looked into the normal physiology of chinchilla eyes and a different tonometer was used in each study, so the reference ranges are not directly comparable, making interpretation of what is a normal IOP more difficult $[7,11,12]$. The aim of our study was to measure the IOP using an applanation tonometer and to add this data to that of the current literature, in order to create a more reliable reference range and enable the clinician to better interpret IOP values obtained during clinical examinations of the chinchilla.

\section{MATERIALS AND METHODS}

Thirteen healthy chinchillas, eight males and five females, were brought into the clinic. They ranged from 1.5 to 6.5 years of age and were from $600-900 \mathrm{~g}$ in weight. All 13 chinchillas were tested for tear production and ten of them were tested for their IOP. The chinchillas had no obvious eye pathologies and were in good general health. They were tested in groups of three or four and the procedures were carried out at approximately the same time in the morning, generally between 08:30 and 09:30 a.m. The same experienced person restrained the chinchillas each time, using a towel, with one hand around the thorax and one supporting the lower body. The same restraint was used for all tests and they were all performed by the same experienced person. The paper point tear test was measured initially, after which, one drop of anaesthetic was placed into each eye; the chinchilla was then put back whilst the next chinchilla went through the same procedure. Once the last chinchilla received the anaesthetic, the first was brought out again, restrained, the IOP measured and then the PPTT II performed.

Roeko Colour No. 30 endodontic paper points (Coltene, Altstätten, Switzerland) were used for this test; a cm ruler was necessary for the measurement of the wetted point and a stopwatch was used to time the test accurately. This specific type of paper point was chosen as it was used in previous studies of tear secretion in rabbits, black tufted marmosets, rats and mice $[4,5,6]$.

The paper point was placed into the lower fornix of the left eye, the stopwatch started and a few seconds later, a second paper point was placed in the right eye taking note of the time of insertion according to the stopwatch. The paper points were then removed in turn, after each one had been in placed for exactly one minute. The tear uptake was immediately measured by lightly pressing the inserted end onto a ruler, causing the point to bend where the tear level reached. The length of the wetted strip was then read off the ruler in millimetres and recorded.

One drop of $0.4 \%$ oxybuprokainium chloride (Benoxi, Unimed Pharma) was administered to each eye and left to work for at least ten minutes. The IOP was measured using the Tonopen Avia ${ }^{\circledR} \operatorname{Vet}^{\mathrm{Tm}}$ (Reichert, New York, USA); three measurements were taken and averaged for each eye. Following the IOP testing, any excess tears were removed using a sterile cotton tipped applicator and the PPTT II was measured in the same manner as previously described for the PPTT I.

The Wilcoxon Signed Ranks Test was used to compare the left and right eyes, and the PPTT I and II values. The Mann Whitney $U$ test was used to compare the males and females. The Spearman's rank-order correlation test was 
calculated to investigate any linear correlation between the ages and the three ophthalmologic parameters. The data were considered to be statistically significant when $\mathrm{P}<0.05$, in which case, the null hypothesis would be rejected. The results were expressed as the mean \pm SD.

\section{RESULTS}

All results are presented in Tables $1-4$. Table 1 shows the overall mean \pm SD for all three tests from both eyes of each chinchilla. Table 2 shows the confidence interval and overall range of results recorded for all three tests. Table 3 and 4 compared the mean \pm SD of the left and right eyes and the male and female chinchillas respectively.

After the statistical analysis it was found that there was no difference in the PPTT I between the left and right eyes $(\mathrm{P}=0.48)$ or between the males and females $(\mathrm{P}=0.09)$ and there was no correlation between the PPTT I and age $(\mathrm{P}=0.61)$. There was also no difference in the IOP between the left and right eyes $(P=0.26)$ but there was a significant difference in the IOP between the males and females $(\mathrm{P}=$ 0.01 ) with the males showing a higher mean IOP (Table 4). There was no difference in the PPTT II between the left and right eyes $(\mathrm{P}=0.58)$ or between the males and females $(\mathrm{P}=0.20)$ and there was no correlation between the PPTT II and age $(\mathrm{P}=0.15)$. The PPTT II was, on average, $22 \%$ higher than the PPTT I (Table 1) and this difference was found to be significant $(\mathrm{P}=0.03)$.

\section{DISCUSSION}

The paper point tear test proved to be accurate and easy to perform, allowing both eyes to be measured almost simultaneously, and caused minimal discomfort to the chinchillas. The rigidity of the paper point allowed it to be easily inserted into the eye and with one or two exceptions, it stayed in place for the entire minute. The paper point tear test proved to be a useful method of measurement of the aqueous tear production in the chinchillas. It seems to be more reliable than the modified Schirmer tear test, as each paper point is exactly the same and it is easier to read and interpret than the STT when aqueous tear volumes are low.

Our data were in a similar range to that of the PPTT in other small mammals, with a higher mean than rats $(6.18$
Table 1. Paper point tear tests and the intraocular pressure results

\begin{tabular}{cccc}
\hline & $\begin{array}{c}\text { PPTT I } \\
{\left[\mathrm{mm} \cdot \mathrm{min}^{-1}\right]}\end{array}$ & $\begin{array}{c}\text { IOP } \\
{[\mathrm{mmHg}]}\end{array}$ & $\begin{array}{c}\text { PPTT II } \\
{\left[\mathrm{mm} \cdot \mathrm{min}^{-1}\right]}\end{array}$ \\
\hline $\begin{array}{c}\text { Overall } \\
\text { Mean } \pm \text { SD }\end{array}$ & $7.98 \pm 1.95$ & $28.52 \pm 12.48$ & $9.71 \pm 3.52$ \\
\hline
\end{tabular}

Table 2. Paper point tear tests and the intraocular pressure confidence intervals and reference ranges

\begin{tabular}{cccc}
\hline & $\begin{array}{c}\text { PPTT 1 } \\
{\left[\mathrm{mm} \cdot \mathrm{min}^{-1}\right]}\end{array}$ & $\begin{array}{c}\text { IOP } \\
{[\mathrm{mmHg}]}\end{array}$ & $\begin{array}{c}\text { PPTT II } \\
{\left[\mathrm{mm} \cdot \mathrm{min}^{-1}\right]}\end{array}$ \\
\hline $\begin{array}{c}95 \% \mathrm{Cl} \\
\text { of the } \\
\text { Mean Range }\end{array}$ & $7.19-8.77$ & $22.68-34.36$ & $8.29-11.13$ \\
& $5.0-11.5$ & $5.00-49.67$ & $4.0-16.0$ \\
\hline
\end{tabular}

Table 3. Paper point tear tests and the intraocular pressure in the left and right eyes

\begin{tabular}{cccc}
\hline & $\begin{array}{c}\text { PPTT 1 } \\
{\left[\mathrm{mm} \cdot \mathrm{min}^{-1}\right]}\end{array}$ & $\begin{array}{c}\text { IOP } \\
{[\mathrm{mmHg}]}\end{array}$ & $\begin{array}{c}\text { PPTT II } \\
{\left[\mathrm{mm} \cdot \mathrm{min}^{-1}\right]}\end{array}$ \\
\hline $\begin{array}{c}\text { Left eye } \\
(\text { Mean } \pm \text { SD })\end{array}$ & $8.23 \pm 2.17$ & $30.07 \pm 12.84$ & $9.12 \pm 3.59$ \\
$\begin{array}{c}\text { Right eye } \\
(\text { Mean } \pm \text { SD })\end{array}$ & $7.73 \pm 1.76$ & $26.97 \pm 12.60$ & $10.31 \pm 3.49$ \\
\hline
\end{tabular}

Table 4. Paper point tear tests and the intraocular pressure

\begin{tabular}{cccc}
\hline & $\begin{array}{c}\text { PPTT 1 } \\
{\left[\mathrm{mm} \cdot \mathrm{min}^{-1}\right]}\end{array}$ & $\begin{array}{c}\text { IOP } \\
{[\mathrm{mmHg}]}\end{array}$ & $\begin{array}{c}\text { PPTT II } \\
{\left[\mathrm{mm} \cdot \mathrm{min}^{-1}\right]}\end{array}$ \\
\hline $\begin{array}{c}\text { Male } \\
(\text { Mean } \pm \text { SD })\end{array}$ & $8.5 \pm 1.9$ & $35.50 \pm 9.31$ & $10.4 \pm 3.1$ \\
$\begin{array}{c}\text { Female } \\
(\text { Mean } \pm \text { SD })\end{array}$ & $7.2 \pm 1.7$ & $21.53 \pm 11.57$ & $8.7 \pm 4.0$ \\
\hline
\end{tabular}

$\left.\pm 2.06 \mathrm{~mm} \cdot \mathrm{min}^{-1}\right)$ and mice $\left(4.39 \pm 1.45 \mathrm{~mm} \cdot \mathrm{min}^{-1}\right)$, and a lower mean than rabbits $\left(13.8 \pm 1.5 \mathrm{~mm} \cdot \mathrm{min}^{-1}\right)[4,5,6]$. This is to be expected considering the smaller size of the mice and rats and the higher STT values for rabbits in the literature $\left(5.3 \pm 2.96 \mathrm{~mm} \cdot \mathrm{min}^{-1}\right)[1,2]$.

The PPTT II determines the basal tear secretion, and is compared with the reflex secretion measured by the PPTT I. In our study, the mean PPTT II was higher than 
the mean PPTT I which was contrary to what would be expected. This may have been caused by the process of wiping the excess anaesthetic out of the eye; the same problem that W eiser et al. [14] found when they swabbed the conjunctival sac in the cow. They solved this by waiting a few minutes before performing the test in order to allow the excess anaesthetic to clear naturally. In chinchillas this may not work as well because of their low blink frequency. In our study, there was a delay between adding the anaesthetic and carrying out the test, however, the IOP was measured and the conjunctival sac was dried just prior to the PPTT II test which may have caused some reflex tearing due to the stimulation of structures other than the cornea. These results may also be due to a low corneal sensitivity in chinchillas or a reduction or the absence of reflex tearing in this species. However, Muller et al. [11] found that chinchillas have a low corneal touch threshold (mean $1.5 \pm 0.9 \mathrm{~g}$. $\left.\mathrm{mm}^{-2}\right)$; lower than that of the guinea pig $\left(3.7 \mathrm{~g} \cdot \mathrm{mm}^{-2}\right)$, indicating that corneal sensitivity is similar to other species, for example the horse which has a corneal touch threshold of $1.23 \pm 1.07$ g.mm $\mathrm{mm}^{-2}[13,14]$.

The Tono-Pen applanation tonometer produced some quite variable results with a coefficient of variance of $44 \%$ which is relatively high. The readings obtained by the applanation tonometer are very reliant on the individual operator's technique, as the instrument needs to be gently tapped on the cornea several times for a reading to be taken which leads to a certain level of inherent variability. The level of stress in the animal tested and the amount of pressure applied to the neck region in a struggling animal, for example may also have affected the results [9]. The two studies that used applanation tonometers to test the IOP in the chinchillas found a mean \pm SD of $18.5 \pm 5.75 \mathrm{mmHg}$ using the Mackay-Marg tonometer, and $17.71 \pm 4.17 \mathrm{mmHg}$ using the Tono-Pen XL. The results we obtained were considerably higher with a much larger variability $[2,7]$. The chinchillas were all healthy with no evidence of ocular pathologies so the variability was unlikely to be due to disease or biological variations. More likely, the causes of the variability would be differences in the restraint pressure, especially in the more excitable chinchillas, operator technique, or an increase in stress causing elevated intraocular pressure [9]. A significant difference was found in our study between the mean IOP in the males and females, with the male group showing a larger mean IOP than the female group. Looking at just the female chinchillas, the mean IOP was much closer to what would be expected in the chinchilla based on the current literature. It is possible that the males used in this study were more stressed than the females, leading to a higher IOP. The sample size in our study, however, was too small to make a definitive conclusion regarding the difference in the IOP between the genders but it would be an interesting area for future investigations.

\section{CONCLUSIONS}

The novel endodontic paper point test proved to be very easy to use, the variability of the data was low and reflex tearing in the chinchillas appeared to be minimal. Further studies using this method should be carried out in order to verify the reproducibility of the tests. The intraocular pressure was found to be much higher than that recorded in previous studies and showed a large variability, most likely caused by operator techniques and higher stress levels in the male chinchillas. Further studies should be carried out on these chinchillas to determine if the results were aberrant due to external influences or if these chinchillas naturally have a higher IOP. In the clinical situation it is likely that stressed and excitable animals will be presented to the clinician, so these results, although out of the normal range so far established, are still useful as they reflect values that could be found in a clinical setting. This variability highlights the importance of taking multiple IOP readings in a patient to avoid a false diagnosis of glaucoma.

\section{ACKNOWLEDGEMENTS}

I would like to thank Dr. Martin Kožár for kindly providing us with his chinchillas and for giving up his time to restrain them for us.

\section{REFERENCES}

1. Abrams, K.L., Brooks, D.E., Funk, R.S., 1990: Evaluation of the Schirmer tear test in clinically normal rabbits. Am. J. Vet. Res., 51, 1912-1913.

2. Biricik, H.S., Oğus, H., Sindak, N., Gürkan, T., Hayat, A., 2005: Evaluation of the Schirmer and phenol red thread tests for measuring tear secretion in rabbits. Vet. Rec., 156, 485-487. 
3. Hittmair, K.M., Tichy, A., Nell, B., 2014: Ultrasonography of the Harderian gland in the rabbit, guinea pig, and chinchilla. Veterinary Ophthalmology, 17, 175-183.

4. Lange, R. R., Lima, L., Montiani-Ferreira, F., 2012: Measurement of tear production in black-tufted marmosets (Callithrix penicillata) using three different methods: modified Schirmer's I, phenol red thread and standardized endodontic absorbent paper points. Veterinary Ophthalmology, 15, 376-382.

5. Lange, R. R., Lima, L., Przydzimirski, C., Montiani-Ferreira, F., 2014: Reference values for the production of the aqueous fraction of the tear film measured by the standardized endodontic absorbent paper point test in different exotic and laboratory animal species. Veterinary Ophthalmology, 17, 41-45.

6. Lima, L., Lange, R.R., Turner-Giannico, A., MontianiFerreira, F., 2014: Evaluation of standardized endodontic paper point tear test in New Zealand white rabbits and comparison between corneal sensitivity followed tear tests. Veterinary Ophthalmology, 17, 1-6.

7. Lima, L., Montiani-Ferreira, F., Tramontin, M., Leigue dos Santos, L., Machado, M., Lange, R. R. et al., 2010: The chinchilla eye: morphologic observations, echobiometric findings and reference values for selected ophthalmic diagnostic tests. Veterinary Ophthalmology, 13, Supplement 1, 14-25.

8. Mans, C., Donnelly, T.M., 2012: Chapter 24 - Disease problems of chinchillas. In Quesenberry, K.E., Carpenter, J. W.: Ferrets, Rabbits and Rodents: Clinical Medicine and Surgery, 3rd Edn., Elsevier Saunders, Missouri, 311-325.

9. Miyazaki, Y., Matsuo, T. and Kurabayashi, Y., 2000: Immobilisation stress induces elevation of intraocular pressure in rabbits. Ophthalmic Research, 32, 270-277.
10. Müller, K., Eule, J.C., 2014: Ophthalmic disorders observed in pet chinchillas (Chinchilla lanigera). Journal of Exotic Pet Medicine, 23, 201-205.

11. Müller, K., Mauler, D.A., Eule, J.C., 2010: Reference values for selected ophthalmic diagnostic tests and clinical characteristics of chinchilla eyes (Chinchilla lanigera). Veterinary Ophthalmology, 13, 29-34.

12. Peiffer, R. L., Johnson, P.T., 1980: Clinical ocular findings in a colony of chinchillas (Chinchilla lanigera). Laboratory Animals, 14, 331-335.

13. Trost, K., Skalicky, M., Nell, B., 2007: Schirmer tear test, phenol red thread tear test, eye blink frequency and corneal sensitivity in the guinea pig. Veterinary Ophthalmology, 10, 143-146.

14. Weiser, B., Tichy, A., Nell, B., 2013: Correlation between corneal sensitivity and quantity of reflex tearing in cows, horses, goats, sheep, dogs, cats, rabbits, and guinea pigs. Veterinary Ophthalmology, 16, 251-262.

15. Williams, D., 2007: Rabbit and rodent ophthalmology. EJCAP, 17, 242-252.

Selected paper from the 59th STUDENT SCIENTIFIC CONFERENCE, Section II - Clinical section, held at the University of Veterinary Medicine and Pharmacy in Košice, SR, on April 6, 2016. 